\title{
AS NOVAS TECNOLOGIAS NAS MEDIAÇÕES PEDAGÓGICAS INTERDISCIPLINARES
}

\section{ARTIGO ORIGINAL}

CHAMPANGNATTE, Dostoiewski Mariatt de Oliveira ${ }^{1}$

FERNANDES, Roberto da Silva ${ }^{2}$

CHAMPANGNATTE, Dostoiewski Mariatt de Oliveira. FERNANDES, Roberto da Silva. As novas tecnologias nas mediações pedagógicas interdisciplinares. Revista Científica Multidisciplinar Núcleo do Conhecimento. Ano 05, Ed. 05, Vol. 03, pp. 0513. Maio de 2020. ISSN: 2448-0959, Link de acesso: https://www.nucleodoconhecimento.com.br/educacao/mediacoespedagogicas

\section{RESUMO}

O presente artigo busca discutir como as novas tecnologias da informação e comunicação (NTICs), podem auxiliar nas mediações em práticas interdisciplinares nas escolas, o que poderia possibilitar romper com as barreiras limitadoras das disciplinas curriculares e poderia permitir uma aprendizagem de forma interdisciplinar e aberta. A escola precisa transformar sua estrutura para fazer do conhecimento algo útil e interessante para o educando. Pressupomos se isso pode ser feito através da articulação entre disciplinas. Diante disso, apresentamos o tema fundamentado em base teórica e o apontamos como uma possibilidade, segundo a visão de alguns autores. Por fim, concluímos que, embora ainda seja um desafio a ser alcançado, a interdisciplinaridade na rotina escolar torna-se cada vez mais discutida e necessária diante de uma sociedade onde impera a lei do mercado globalizado que exige cada vez mais profissionais super qualificados e diferenciados em conhecimento. E nesse

\footnotetext{
${ }^{1}$ Pós-Doutor em Comunicação. Doutor em Educação.

${ }^{2}$ Mestre em Humanidades, Culturas e Artes.
} 
contexto, o uso das NTICs, se planejado, permite trabalhar temas com potencial interdisciplinar.

Palavras-chave: Interdisciplinaridade, novas Tecnologias da Informação e Comunicação, mediações pedagógicas.

\section{INTRODUÇÃO}

Vivemos dias em que críticas à escola questionam a fragmentação do ensino que é puramente disciplinar na grande maioria das instituições. Tais críticas apontam a necessidade de uma reorganização das disciplinas e uma reformulação do processo pedagógico de uma forma em que haja um diálogo entre as diversas áreas do saber. Essa proposta interdisciplinar busca propiciar o pensar-com e o pensar-sobre-opensar.

Sem a dialogicidade não há espaço para a construção do conhecimento, pois ela orienta a concepção do mesmo (FREIRE, 2005). Devemos reestruturar antigos processos de ensino no intuito de promover uma visão mais global do mundo ao invés de uma visão fragmentada da totalidade.

Porém, nos deparamos com algumas indagações: Como integrar disciplinas de linguagens aparentemente tão distintas? Como convergir diferentes perspectivas ao ponto de geramos uma visão mais global de mundo e tornar o conhecimento produzido na escola pertinente para o educando? Como as novas tecnologias podem dar suporte a esse contexto?

Diante desses dilemas, vamos procurar confrontar tais indagações, buscando em base teórica fundamentada, esclarecer como as Novas Tecnologias da Informação e comunicação (NTICs) podem dar suporte para a interdisciplinaridade na escola.

Um enfoque interdisciplinar desenvolveria no individuo a capacidade de agregar valores de diferentes áreas do saber, relacionando os mesmos ou completando-os no sentido de solucionar problemas concretos em sua vida. Essa reflexão ou pensamento 
complexo é possível através de um processo de ensino interdisciplinar (MORIN, 2002).

Porém, por diversas vezes o conceito de interdisciplinaridade acaba se perdendo nos em meio aos corredores da escola como se tivesse que superar os descaminhos de um enorme labirinto, isso acaba desmotivando seus adeptos e seguidores que muitas vezes acabam não conseguindo implementar o projeto ou, de outra forma, acabam aceitando de forma passiva sua modificação para algo semelhante, multidisciplinar, ou simplesmente voltam para sua práxis puramente disciplinar.

Este artigo propõe fundamentar nossa reflexão em base teórica fundamentada, nas concepções de alguns autores, como as novas tecnologias podem auxiliar a prática docente em mediações interdisciplinares tornando-as mais participativas, abertas e dinâmicas.

\section{A TECNOLOGIA NAS MEDIAÇÕES}

Estamos inseridos em um contexto de mundo globalizado, instável, perante uma era digital onde aquilo que é visto como certo hoje, amanhã pode não ser mais. O que impulsiona o pensamento científico hoje é a sua capacidade de se auto questionar, livre de autoritarismos e dogmatismos. Nesse contexto, as NTICs ajudam a promover uma aprendizagem mais colaborativa, onde o professor é mais do que um mero facilitador, ele torna-se um "mediador "no sentido de auxiliar o aluno e desafiá-lo para participar de um processo dialógico. Isso possibilita quebrar antigas metodologias expositivas e disciplinares, desde que o professor as utilize para promover discussões construtivas (MASETTO, 2000). O autor destaca que o uso das novas tecnologias nas mediações agrega valores e auxilia o educando na compreensão dos conteúdos.

Isso remete para estudos sobre a interdisciplinaridade em Morin (2002, p.29), onde a interdisciplinaridade torna os sujeitos aptos para "articular, religar, contextualizar, situar-se num contexto e, se possível, globalizar, reunir os conhecimentos adquiridos". Diante disso, indagamos se a mediação feita pelo professor com auxílio das mídias digitais nas práticas interdisciplinares pode colaborar na construção de uma 
aprendizagem dinâmica e emancipadora, pois, tal mediação instiga o aluno a refletir, discutir, colaborar, criar e criar junto.

As novas tecnologias possibilitam a utilização de várias técnicas de mediação pedagógica, usando diferentes suportes midiáticos, estimulando a aprendizagem. $E$ assim como afirma Masetto (2000), elas dão suporte para dinamizarmos as aulas, tornando os cursos mais vivos, interessantes, participativos e tornando os conhecimentos produzidos mais vinculados à nova realidade de estudo.

Masetto (2000) traz a distinção entre os conceitos de ensinar e aprender, ao ensinar o professor apenas transmite conhecimentos para o aluno passivo, já o conceito de aprender envolve o aluno, seus colegas e o professor, tal conceito procura dar significado ao conhecimento, incentiva reflexões, debates e diálogos, integra conceitos teóricos com a prática, compara posições e teorias, onde o professor tem a oportunidade de realizar seu papel de mediador. Nesse cenário, Fazenda (2002), afirma que a interdisciplinaridade se caracteriza por um exercício ativo de busca do conhecimento, no qual perguntamos e duvidamos.

Isso caracteriza um novo processo de liderança e renovação. Uma boa escola hoje, sabe que não se deve mais copiar, colar, repetir, não há mais espaço para se reproduzir conhecimentos adquiridos e repassados ao aluno. Era de acordo com essa lógica que os processos de ensino-aprendizagem criavam seus especialistas, e ainda hoje, as escolas ainda seguem esse modelo. De nada adianta dar para o aluno um conteúdo pronto onde ele possa buscar no livro uma resposta pronta. Muitos indivíduos se apropriam de um saber limitado, uma fatia do saber, sem se preocupar em renovar, criar, explorar novos campos e áreas do conhecimento. Separando as disciplinas, nós criamos uma barreira para o aprendizado. A melhor educação acontece através de um processo de colaboração.

Com relação ao diálogo interdisciplinar, Fazenda (1996) destaca:

Em nível de interdisciplinaridade, ter-se-ia uma relação de reciprocidade, de mutualidade, ou melhor, dizendo, um regime de copropriedade que 
iria possibilitar o diálogo entre os interessados. Neste sentido, pode dizer-se que a interdisciplinaridade depende de uma atitude (FAZENDA, 1996).

Masetto (2000) destaca ainda que o conceito de mediação pedagógica parte da postura do professor, na forma como conteúdos são transmitidos, seu relacionamento com os educandos e sua relação com o contexto, o global. Essas mediações, para ele, podem estar presentes tanto em estratégias convencionais como às ligadas as novas tecnologias.

Masetto ressalta trabalho de Almeida em (in VALENTE 1996, p. 164):

o professor que trabalha na educação com a informática há que desenvolver na relação aluno-computador uma mediação pedagógica que se explicite em atitudes que intervenham para promover o pensamento do aluno, implementar seus projetos, compartilhar problemas sem apontar soluções, ajudando assim o aprendiz a entender, a analisar, testar e corrigir os erros.

As transformações que a sociedade moderna vem sofrendo nos últimos anos, com os avanços tecnológicos, criou nos indivíduos uma nova forma de pensar, de ver o mundo. Os jovens são os mais afetados por essa nova tendência, com o uso do computador eles passaram a ter disponível toda forma de informação, em tempo real, e isso criou transformações psicológicas em seu comportamento. Eles estão acostumados a um retorno instantâneo daquilo que buscam na plataforma digital, o que acaba gerando ansiedade e sede pelo novo, já que nosso cérebro vive alimentando-se de dados novos.

Em escolas tradicionalistas, o professor precisa se desdobrar para chamar a atenção de seus alunos. É praticamente impossível manter sua atenção apenas com um quadro branco e livros didáticos coloridos. A verdade é que não dá mais. Temos que nos conscientizar de que eles vivem plugados em seus MP3, e suas consciências conectadas aos smartphones e às redes sociais. Torna-se urgente e necessário 
difundirmos novos conceitos e incluirmos às práticas pedagógicas esse mundo tecnológico venerado pelos jovens.

Destacamos também a necessidade de cursos de aperfeiçoamento docente para utilizar as NTICs, elas ainda possuem muito potencial que não está sendo utilizado. Muitos professores as utilizam meramente com intuito ilustrativo, sem agregar valores e sem promover a dialogicidade em suas práticas. O despreparo dos docentes para compreender e lidar com as mídias digitais tem se mostrado um problema, já que muitos docentes cultivam a ideia de que seus alunos sabem lidar melhor com o computador do que eles. Esse estigma pode ser quebrado por meio de cursos de capacitação.

Moraes (1993) destaca:

(...) pensar na formação do professor para exercitar uma adequada pedagogia dos meios, uma pedagogia para a modernidade, é pensar no amanhã, numa perspectiva moderna e própria de desenvolvimento, numa educação capaz de manejar e produzir conhecimento(...). (MORAES, 1993, p.23)

Entendemos que o conhecimento deve ser compartilhado e despertar o senso crítico.Com as constantes mudanças em nossa sociedade, devemos incorporar novos recursos como apoio, criando novos ambientes de aprendizagem através de uma perspectiva sócio interacionista.

Para que as mídias digitais possam quebrar as fronteiras das disciplinas e promover uma aprendizagem mais aberta (SANTOS, 2009), a fragmentação do conhecimento não pode ser um empecilho. Ao integrar som-imagem-ideias para auxiliar na compreensão de conteúdos, as mídias dão suporte para que o objeto de estudo possa ser discutido sob potencial interdisciplinar.

O conhecimento fragmentado tão criticado e combatido por Pinheiro, Edgar Morin, Ivani Fazenda, entre outros, foi a base de formação de grande parte do professorado e isso gera incertezas por parte dos docentes que buscam engajar-se em projetos 
interdisciplinares. Para tal, o professor necessitaria de tempo para se dedicar à leitura e à capacitação, efetivando assim esse processo de engajamento onde ele busca propiciar condições para a troca com outras disciplinas, e consequentemente, ele deve buscar também redefinir sua práxis, senão as reuniões para se discutir projetos interdisciplinares estariam fadadas ao fracasso.

Fazenda (2002, p. 78) afirma:

Aquele que se aventura a empreender esse caminho precisa antes de mais nada assumir um sério compromisso com a erudição; e com a erudição em múltiplas direções. Buscar o conhecimento, uma das atitudes básicas a serem desenvolvidas em quem pretende empreender um projeto interdisciplinar, só pode ser entendido no seu exercício efetivo.

Muitos são atraídos pela mudança, pela necessidade de respostas para questões complexas desenvolvidas em sala de aula e pela motivação de participar de uma proposta diferente, algo novo.

A questão primordial é: como integrar interdisciplinaridade em sala de aula com as mídias digitais?

As novas tecnologias de informação e comunicação (NTICs) podem ser usadas em sala de aula para agregar valores ao conteúdo da aula, e por meio de discussões e interação professor-alunos-tecnologia, motivá-los para as aulas e torná-los sujeitos produtores de conhecimento (MASETTO, 2000). Eles aprendem sozinhos a articular pensamentos em ambientes virtuais coletivos de interação. Por que não trazer essa habilidade para se discutir temas mediados pela tecnologia em sala de aula?

Ao discutir as mediações pedagógicas e as novas tecnologias, Masetto (2000) destaca que as novas tecnologias devam ser usadas também no desenvolvimento da interaprendizagem, produto de suas inter-relações com colegas e outras pessoas, até chegar à constituir um conhecimento que seja significativo para ele, que auxilie na compreensão de sua realidade cotidiana e social e até mesmo interferir nela. 
Masetto ressalta trabalho de Perez e Castillo (1999) que afirmam que a mediação pedagógica busca abrir caminhos para novas relações do estudante com seu contexto, com os colegas, consigo, com seu futuro através de características inerentes às mediações como: dialogar, trocar experiências, debater dúvidas, questões ou problemas, desencadear reflexões, estabelecer conexões entre o conhecimento adquirido e novos conceitos, colaborar para que se aprenda a comunicar aquilo que foi aprendido seja por intermédio das novas tecnologias ou por meios convencionais, entre outras.

Isso remete à interdisciplinaridade segundo Pinheiro (2006), pois:

(...) a interdisciplinaridade escolar tem como finalidade a difusão do conhecimento (favorecer a integração de aprendizagens e conhecimento) e a formação de atores sociais e tem como consequência o estabelecimento de ligações de complementaridade entre as disciplinas escolares. (PINHEIRO, 2006, p.80-81)

Tais ligações de complementariedade entre as disciplinas possibilitariam que um objeto ou conteúdo fosse visto por vários olhares, olhares plurais. Porém, o diálogo entre as disciplinas, de acordo com Fazenda (1993), deve permitir um pensar interdisciplinar onde as formas de conhecimento deixam-se interpenetrar-se.

Ao utilizar as NTICs, o docente ajuda a desenvolver no aluno um pensamento complexo através de um aprendizado colaborativo onde ele consegue apreender melhor o conhecimento e perceber que tudo está interligado, interconectado. Nesse contexto, Santos (2009) afirma que diante de tantas inovações tecnológicas e de um fluxo cada vez maior de informações circulando, há a necessidade que o professorado se conscientize que "as NTICs permitem novas possibilidades e formatos educativos, pois rompem as barreiras limitadoras das disciplinas curriculares ao permitir aprender de forma interdisciplinar e aberta" (SANTOS, 2009, p.37).

Podemos inferir que ao rompermos as barreiras limitadoras das disciplinas, permitiríamos ao aluno desenvolver um pensamento complexo através de um enfoque 
interdisciplinar. Contudo, cabe a ressalva: Teria o aluno autonomia para integrar diferentes perspectivas, de diferentes áreas do conhecimento, relacionando-as ou comparando-as para solucionar problemas complexos do cotidiano?

Entretanto, não adianta você ter uma sala equipada com tecnologia de última geração e não inovar em nada, não usar a criatividade, não promover discussões, o tecnológico tem que caminhar simultaneamente com o metodológico. Além disso, uma prática interdisciplinar favorece a aprendizagem colaborativa onde o aluno tem que interagir com informações de diferentes áreas do saber, com colegas e professores. Nesse contexto, as NTICs possibilitam diferentes abordagens de conteúdo e a interação dos mesmos com outras áreas disciplinares.

Pinheiro (2006) chama a atenção para a interdisciplinaridade na prática escolar, que, segundo ele, não deve ser reduzida a uma simples comunhão de temas que resultaria em algo multidisciplinar, que embora também seja facilitadora nos processos de ensino-aprendizagem, não alcança todas as possibilidades e resultados provenientes de uma prática interdisciplinar.

Devemos, portanto, estar atentos, pois, a simples comunhão de conceitos discutidos em sala de aula pressupõe uma interação, mas nada indica que haverá uma integração. As NTICs usadas como ferramenta pedagógica possibilitam a articulação de algumas abordagens de disciplinas que possibilitariam discutir o objeto de estudo ou conteúdo abordado em sala de aula de forma interdisciplinar. Assim, o objeto adquire potência de discussão interdisciplinar.

Para aqueles que desejam engajar-se em uma prática interdisciplinar na escola, isso requer tempo e empenho. A maioria do professorado teve uma formação disciplinar, e como pressuposto acaba ensinando da mesma forma que aprendeu.

\section{CONSIDERAÇÕES FINAIS}

A escola de hoje sabe que deve formar cidadãos críticos que saibam questionar, refletir, avaliar, criar, recriar, colaborar, fazer junto. Ela deve servir para inspirar o 
educando, fazê-lo estabelecer critérios, ter noção, pois, uma pessoa sem noção não chega a parte alguma. Tendo critérios, ele deve dentro de um oceano de informações, saber selecionar, diferenciar o conhecimento mais importante, e este deve ser significativo em seu cotidiano. Para isso, é fundamental que os conteúdos relacionados às disciplinas estejam bem articulados, através de uma proposta interdisciplinar. Ao tentarmos estabelecer um paralelo entre ações, percepções e entendimentos acerca da maneira como o conhecimento é transmitido, isso permitirá ao educando uma perspectiva histórica, filosófica, social, política e econômica, atendendo assim aos requisitos básicos para uma educação globalizada.

Almeja-se que este artigo possa corroborar para elucidar questões relacionadas ao uso das novas tecnologias da informação e comunicação como auxílio para o desenvolvimento de atividades e projetos interdisciplinares na escola.

Por fim, se pretendemos implementar novos métodos de ensino, a interdisciplinaridade se mostra como uma opção, que embora ainda seja uma desafio a ser trabalhado pelo professorado, abre um leque de possibilidades objetivando educandos mais reflexivos, críticos, interessados, através de um processo de ensinoaprendizagem que, quem sabe, possa ser mais eficaz.

\section{REFERÊNCIAS}

FAZENDA, Ivani Catarina Arantes. Interdisciplinaridade: história, teoria e pesquisa. 10 ed. Campinas: Papirus, 2002.

Interdisciplinaridade: definição, projetos, pesquisa. In: Práticas interdisciplinares na escola. 2ed. São Paulo: Cortez, 1993.

FREIRE, Paulo. Pedagogia do Oprimido. Rio de Janeiro: Paz e terra, 2005.

MASETTO, Marcos. Mediação pedagógica e o uso da tecnologia. In: MORAN, José Manuel; MASETTO, Marcos; BEHRENS, Marilda Aparecida. Novas tecnologias e mediação pedagógica. Campinas, SP: Papirus. 2000. 
MORAES, Maria Cândia). O paradigma educacional emergente. Campinas: Papirus, 1993.

MORIN, Edgar. Educação e complexidade: os sete saberes e outros ensaios. São Paulo: Cortez, 2002.

PINHEIRO, Thais. As contribuições da Geografia para a abordagem interdisciplinar no ensino médio. Dissertação (Mestrado em Educação Científica e Tecnológica) Universidade Federal de Santa Catarina, Santa Catarina, 2006.

SANTOS, Margarida Maria Calafate. As novas tecnologias em projetos interdisciplinares na escola pública - um estudo à luz da Teoria da Atividade. Dissertação de Mestrado (Programa de Interdisciplinar de Linguística Aplicada) - Universidade Federal do Rio de Janeiro. Rio de Janeiro, 2009.

Enviado: Março, 2020.

Aprovado: Maio, 2020. 